\title{
Uncomplicated post-dated pregnancy in one horn of bicornis bicollis uterus
}

\author{
Preet Kamal Bedi, Arunima Saini*, Nisha Bhagat
}

Department of Obstetrics and Gynecology, Government Medical College, Amritsar, Punjab, India

Received: 24 June 2018

Accepted: 26 July 2018

\section{*Correspondence:}

Dr. Arunima Saini,

E-mail: arunima0123@gmail.com

Copyright: (C) the author(s), publisher and licensee Medip Academy. This is an open-access article distributed under the terms of the Creative Commons Attribution Non-Commercial License, which permits unrestricted non-commercial use, distribution, and reproduction in any medium, provided the original work is properly cited.

\begin{abstract}
Mullerian anomalies result from abnormal fusion of mullerian ducts (paramesonephric ducts). The prevalence of $1-10 \%$ is seen in general population. Patients with uterine anomalies have chances of infertility, miscarriage, preterm labor, cervical incompetence and are an independent risk factor for uterine rupture. Just a few pregnancies are carried forward till term without any maternal and fetal complications. Here we report a rare case of bicornuate uterus bicollis that successfully conceived, carried her pregnancy beyond her expected date of delivery (4 days overdue) and delivered a full-term baby without any significant complications.
\end{abstract}

Keywords: Bicornuate uterus bicollis, Mullerian anomaly

\section{INTRODUCTION}

The normal development of the female reproductive tract involves a chain of processes beginning with the differentiation, migration, fusion and then subsequent canalization of the Müllerian system. Various uterine malformations can occur due to abnormal fusion of paramesonephric ducts. ${ }^{1}$ The overall prevalence is $1-10 \%$ in unselected population, $2-8 \%$ in subfertile women and $5-30 \%$ of women with a history of miscarriage. ${ }^{2}$ Uterus bicornis bicollis is characterized by a double or single vagina, double cervix and two single-horned uteruses which show a partial fusion of their muscular walls with duplication extending down to the uterine orifice. Although the bicornuate uterus does not lead to reduced fertility, it is frequently associated with adverse pregnancy outcomes such as recurrent abortions, miscarriages, preterm births, fetal growth restricted babies and rarely end up in an uncomplicated full-term pregnancy. The most common symptomatic presentation is with early pregnancy loss and cervical incompetence. ${ }^{3}$
Studies have shown that uterine rupture might occur during pregnancy because of a thin wall and inability of malformed uterus to expand to an extent a normal one can. ${ }^{4}$ The pregnancies carried in a bicornuate uterus fall in the high-risk category and therefore need earlier detection and rigorous follow-up throughout the pregnancy to detect the complications at their earliest.

\section{CASE REPORT}

Ms. X, 26 years female reported to emergency on 7th February 2018, being referred from a government hospital on account of postdated pregnancy. She was a primigravida married since two years, with 40 weeks 4 days period of gestation, sure of her date of last menstrual period. On clinical examination, she was calm, conscious, co-operative, well oriented to time, place and person. Her vitals were stable and had an average built and nutrition. Per abdomen examination revealed a single fetus in oblique lie with breech lying in the right subchondral region and vertex presentation. The head was 5/5 
palpable. The fetus seemed to be relatively stuck with minimal liquor. On per vaginum examination, a midline non-communicating longitudinal septum was felt traversing throughout the vagina. The septum was reaching upto the cervical canal and dividing it into two equal halves. Both cervices were admitting two fingers, minimally effaced with flat membranes and fetal head could be felt through the both the cervical openings. She had only one ultrasonography report in second trimester which showed a single live fetus of 24 weeks corresponding to her gestation by Last Menstrual Period (LMP) with adequate liquor. However, no uterine anomaly was detected in that ultrasound. Investigations revealed that her hemoglobin level was $10.0 \mathrm{~g} / \mathrm{dl}$, blood group was B positive, hepatitis B surface antigen was negative, non-reactive HIV screening, and urinalysis was within the normal limits. Blood was arranged and after counseling of patient and her attendants, emergency caesarean section was done under spinal anaesthesia. Intra-operatively, the uterus was bicornuate with a fullterm pregnancy in the right horn as seen in Figure 1.

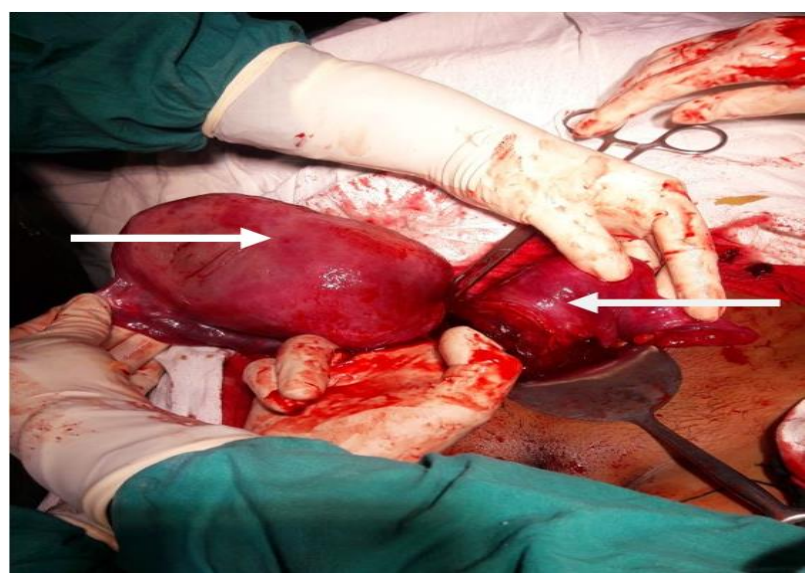

Figure 1: Arrows showing bicornuate uterus with a smaller left horn.

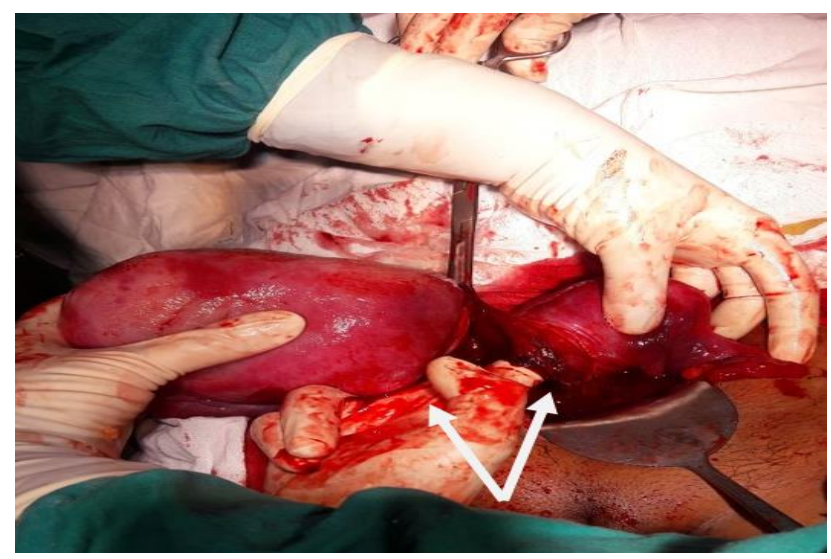

Figure 2: Arrows showing lower uterine segment communicating with both uterine cavities.

An alive term male baby weighing $3.0 \mathrm{~kg}$ was delivered, cried immediately at birth with an APGAR score of 9/10 at 1 minute and 10/10 at 5 minutes. There was no gross congenital malformation in the baby. The liquor was scanty. The placenta was postero-fundal, the uterine tubes and the ovaries were grossly normal on both sides. The intra-operative blood loss was $500 \mathrm{ml}$. The left horn was small, measuring $5 \times 3 \mathrm{~cm}$. Both the horns communicated in the lower uterine segment where the head was impacted as seen in Figure 2. The vaginal septum extending upto cervical os could be visualized and felt. The postoperative period was uneventful, and the patient was discharged on $9^{\text {th }}$ postoperative day after removal of stitches. Patient reported in outpatient department after 6 weeks for regular follow-up with a healthy baby.

\section{DISCUSSION}

The incidence of congenital uterine malformation is estimated to be $3-5 \%$ in general population. Most widely accepted classification was given by sub-committee of the American Fertility Society (now the American Society of Reproductive Medicine) in 1986. Bicornuate uteri belong to class IV. ${ }^{5}$ There is partial fusion of the paramesonephric ducts. Most of the women with a bicornuate uterus are asymptomatic but may present with dyspareunia or dysmenorrhea in the presence of a thick, sometimes obstructing, vaginal septum which is present in $25 \%$ of the patients. Most common symptomatology in bicornuate uterus is cervical incompetence requiring cerclage operation. ${ }^{6}$ Sometimes there may be associated abnormalities of renal tract as in other mullerian anomalies. However, studied patient had history of dyspareunia but she conceived spontaneously with virtually uneventful pregnancy.

Bicornuate uterus may be an independent risk factor for uterine rupture irrespective of the gestation and parity of patient. A rare case of bicornuate uterus rupture in a full term pregnancy have been reported. ${ }^{7}$ Rare cases of early detection of bicornuate bicollis uterus with unilateral cervical atresia in teenager female presenting with chronic debilitating pain have been reported in literature. ${ }^{8}$ An interesting case of uterus bicornis bicollis with six months pregnancy in right horn and pyometra in left horn has also been reported. ${ }^{9}$ Some studies have shown the risk of both deformations (limb contractures, scoliosis, and club foot) and malformations (omphalocele, teratoma, microcephaly and acardia-anencephaly) in babies born to such uterine anomaly patients. ${ }^{10,11}$

Diagnostic workup includes proper history, ultrasonographic examination, hysteroscopy, sonosalpingography, laparoscopy, hysterosalpingography and Magnetic Resonance Imaging in infertile patients. ${ }^{12}$ Sonography, though useful in diagnosing uterine anomalies, is operator-dependent and may be missed as in studied case. Women with bicornuate uteri have a $62.5 \%$ chance of having a live birth and $25 \%$ risk of preterm birth and spontaneous abortion. ${ }^{13}$ Surgical corrections like Strassman's Metroplasty may be needed in patients with poor reproductive outcome. ${ }^{14}$ Majority of 
the patients land up in maternal or fetal complications thereby halting the normal progress till the expected date of delivery. One case of successful pregnancy in bicornis bicollis uterus has been reported carrying till 36 weeks of pregnancy. ${ }^{15}$ Till date, no other case has been reported in literature to the best of author's knowledge. Present case report is unique having a postdated pregnancy with minimal complications and good fetal outcome.

\section{CONCLUSION}

This is a case of bicornuate uterus (bicornis bicollis) with a communicating horn which was successfully carried undiagnosed till term gestation, more so 4 days postdated. Women should be counseled to get their regular antenatal check-up so as to detect such pregnancies earlier rather than landing in emergency room directly. This could have helped render extra care to the patient thereby decreasing the risk of both maternal and fetal complications. A high index of suspicion should be kept at each stage for improving fetomaternal outcome in future.

Funding: No funding sources

Conflict of interest: None declared

Ethical approval: Not required

\section{REFERENCES}

1. Adeyemi AS, Atanda OO, Adekunle AD. Successful pregnancy in one horn of a bicornuate uterus. Annals of African medicine. 2013;12(4):252.

2. Raga F, Bauset C, Remohi J, Bonilla-Musoles F, Simón C, Pellicer A. Reproductive impact of congenital Müllerian anomalies. Hum Reprod (Oxford, England). 1997;12(10):2277-81.

3. Nahum GG. Uterine anomalies. How common are they, and what is their distribution among subtypes? J Reprod Med. 1998;43(10):877-87.

4. Jayaprakash S, Muralidhar L, Sampathkumar G, Sexsena R. Rupture of bicornuate uterus. BMJ Case Reports. 2011; 2011(10):1-4.

5. The American fertility society classifications of adnexal adhesions, distal tubal obstruction, tubal occlusion secondary to tubal ligation, tubal pregnancies, mullerian anomalies and intrauterine adhesions. Fertil Steril. 1988;49:944-55.
6. Golan A, Langer R, Wexler S, Segev E, Niv D, David MP. Cervical cerclage--its role in the pregnant anomalous uterus. Int J Fertil. 1990;35(3):164-70.

7. Nitzsche B, Dwiggins M, Catt S. Uterine rupture in a primigravid patient with an unscarred bicornuate uterus at term. Case Reports Women's Health. 2017;15:1-2.

8. Dohbit JS, Meka E, Tochie JN, Kamla I, Mwadjie D, Foumane P. A case report of bicornis bicollis uterus with unilateral cervical atresia: an unusual aetiology of chronic debilitating pelvic pain in a Cameroonian teenager. BMC Women's Health. 2017;17(1):39.

9. Marshall GB. Case of Uterus Bicornis Bicollis; Six Months' Pregnancy Right Horn, Pyometra Left Horn. BJOG: Int J Obstet Gynaecol. 1914;25(4):197-200.

10. Martínez-Frías ML, Bermejo E, Rodríguez-Pinilla E, Frías JL. Congenital anomalies in the offspring of mothers with a bicornuate uterus. Pediatrics. 1998 Apr 1;101(4):e10.

11. Winter RM, Dearlove J, Jolly H, Pawson N, Wilson RG. Apparent microcephaly caused by a bicornuate uterus. $\mathrm{Br}$ Med J (Clin Res Ed). 1983;286(6378):1640-1.

12. Raga F, Bonilla-Musoles F, Blanes J, Osborne NG. Congenital Müllerian anomalies: diagnostic accuracy of three-dimensional ultrasound. Fertil Steril. 1996;65(3):523-8.

13. Braun P, Grau FV, Pons RM, Enguix DP. Is hysterosalpingography able to diagnose all uterine malformations correctly? A retrospective study. Eur J Radiol. 2005;53(2):274-9.

14. Kruger TF, Matsaseng T. Laparoscopic Strassman's metroplasty for bicornuate uterus-is it relevant?: case report. South Afr J Obstet Gynaecol. 2012;18(3):857.

15. Suhail MF, Khan H, Suhail S. Congenital uterine anomaly: Pregnancy in a woman with bicornis bicollis uterus. Indian $\mathbf{J}$ Practising Doctor. 2008;(5)1:3-4.

Cite this article as: Bedi PK, Saini A, Bhagat N. Uncomplicated post-dated pregnancy in one horn of bicornis bicollis uterus. Int J Reprod Contracept Obstet Gynecol 2018;7:3890-2. 